\title{
Analisa FEM pada Desain Botol Plastik Kemasan yang dapat Digunakan Ulang sebagai Bahan Konstruksi Bangunan
}

\author{
Norman Iskandar, Muhammad Ikhsan*, Muhammad Iqbal Mudzakky, Daniel Dwi Putra Wibowo \\ Departemen Teknik Mesin, Fakultas Teknik, Universitas Diponegoro \\ Jl. Prof. Sudharto, SH., Tembalang-Semarang 50275, Telp. +62247460059 \\ *E-mail: ikhsan@student.undip.ac.id
}

\begin{abstract}
In this paper, we create a new design of reusable plastic bottle, which can reuse as building bricks called Rubicks v. 2.1 with some upgrade of the design that can reinforce static strength when the body of bottle applied by a force. The purpose of this research are to find and to analyze the magnitude of force that can make the design of bottle will be fail or damage. The method that used in this paper is Finite Element Method (FEM). In this paper, the bottle given ten of variation magnitude of forces from $200 \mathrm{~N}$ to $2000 \mathrm{~N}$. The result and analyze that the lowest total deformation value is $0.22 \mathrm{~mm}$ and the highest total deformation value is $2.25 \mathrm{~mm}$. For Maximum Shear Stress, the lowest maximum shear stress is when the bottle applied $200 \mathrm{~N}$ each is $3.66 \mathrm{MPa}$. Meanwhile, the highest maximum shear stress is when the bottle is applied $2000 \mathrm{~N}$ each is $36.65 \mathrm{MPa}$. The most effective of safety factor is chosen when the bottle have a value of safety factor equal or more than 1. The magnitude of force that can applied on the Rubicks v. 2.1 plastic bottle design is $1700 \mathrm{~N}$.
\end{abstract}

Kata kunci: Bottle, Force, FEM, Deformation, Safety Factor, Maximum Shear Stress

\section{Abstrak}

Pada penelitian ini, kami membuat sebuah desain botol plastik baru yang dapat digunakan kembali (Reusable Bottle) yang bernama Rubicks v. 2.1 dengan beberapa peningkatan fungsional pada desain botol yang berfungsi untuk menambah kekuatan statik saat badan botol tersebut diberi gaya. Tujuan dari penelitian ini adalah untuk mengetahui dan menganalisa desain botol tersebut sampai titik luluh atau sampai plastis. Metode yang digunakan pada panelitian ini adalah Metode Elemen Hingga (MEH). Pada peneitian ini, digunakan sepuluh variasi gaya yang diberikan pada permukaan muka botol dari 200 N sampai 2000 N. Didapatkan hasil dan analisa bahwa deformasi total yang paling rendah sebesar $0.22 \mathrm{~mm}$ dan deformasi total terbesar yang dihasilkan adalah $2.25 \mathrm{~mm}$. Tegangan geser maksimum, memiliki nilai paling kecil saat botol diberikan gaya sebesar $200 \mathrm{~N}$ yaitu 3.66 MPa. Sedangkan tegangan geser maksimum paling besar yaitu ketika botol diberikan gaya sebesar $2000 \mathrm{~N}$, yaitu 36.65 $\mathrm{MPa}$. Faktor keamanan paling efektif ditentukan ketika botol tersebut memiliki faktor keamanan lebih besar atau sama dengan 1. Gaya yang mampu diberikan pada desain botol plastik Rubicks v. 2.1 adalah sebesar $1700 \mathrm{~N}$.

Kata kunci: Botol, Gaya, MEH, Deformasi, Faktor Keamanan, Tegangan Geser Maksimum.

\section{Pendahuluan}

Sampah plastik merupakan masalah lingkungan hidup yang sedang dihadapi oleh dunia. Dikutip dari The New Republic, diperkirakan 19 miliar pon plastik yang berakhir di lautan setiap tahun dan diperkirakan juga akan meningkat dua kali lipat pada tahun 2025 [1]. Terdapat 5 besar negara penyumbang sampah botol plastik terbanyak, yaitu Tiongkok (10.42 Miliar), Amerika Serikat (10.13 Miliar), Meksiko (8.23 Miliar), Indonesia (4.82 Miliar), Brazil (4.80 Miliar). Dari data tersebut dapat diperkirakan total sampah botol plastik di dunia diatas 50 Miliar [2].

Hal tersebut disebabkan oleh konsumsi plastik masyarakat dunia yang banyak pada setiap kebutuhan sehingga konsumsi plastik di dunia sangat tinggi. Minimnya pengetahuan mengenai pengelolaan sampah berbahan plastik di beberapa negara juga menyebabkan upaya pengurangan dari dampak sampah plastik di dunia tidak optimal.

Salah satu jenis sampah plastik yang paling banyak ditemukan adalah kemasan botol plastik. Kemasan botol plastik terbuat dari bahan dasar PET (Polyethylene Terephthalate). Jenis plastik ini memiliki struktur dan sifat material yang transparan, termoplastik, kuat dan lentur [3]. Struktur dan sifat tersebut menjadikan material PET ini menjadi bahan dasar botol plastik. Namun, bahan dasar plastik ini mempunyai dampak yang buruk bagi lingkungan, yaitu membutuhkan waktu 450 untuk terurai secara keseluruhan [4].

Saat ini, terdapat beberapa terobosan baru dalam menangani permasalahan sampah botol plastik di dunia, yaitu menciptakan sebuah desain botol plastik yang dapat langsung digunakan kembali sering disebut Reusable Bottle. Penemuan ini sudah banyak dikembangkan dan diteliti bahkan mulai diaplikasikan di berbagai belahan dunia. Seperti contoh model botol bernama PET(b)rick 1.0 yang sudah dipatenkan yang merupakan sebuah desain botol plastik yang 
terbuat dari PET (Polyethylene Terephthalate) yang dapat disusun sebagai bahan bangunan [5-6]. Selain PET(b)rick 1.0, terdapat sebuah desain botol plastik yang memiliki fungsi yang sama namun memiliki bentuk yang sederhana, yaitu bernama BotBrik [7].

Pada penelitian ini, penulis membuat sebuah desain botol plastik yang dapat digunakan kembali setelah habis konsumsi yang bernama Rubicks v. 2.1. Desain botol yang dapat menambah kekuatan saat badan botol tersebut diberi gaya. Tujuan dari penelitian ini adalah untuk mengetahui dan menganalisa desain botol tersebut sampai titik luluh atau sampai plastis dengan Metode Elemen Hingga.

\section{Material dan Metode Penelitian}

\subsection{Metode Elemen Hingga}

Pada penelitian ini, menggunakan Metode Elemen Hingga (MEH) dengan batasan-batasan yang digunakan pada sebuah penelitian. Jenis material yang digunakan pada Metode Elemen Hingga ini adalah Polyethylene Terephthalate (PET) dengan spesifikasi yaitu massa jenis sebesar $1350 \mathrm{~kg} / \mathrm{m} 3$, Young Modulus sebesar 2.76 GPa, Poisson's Ratio sebesar 0.42, Yield Strength 59.3 MPa, Ultimate Tensile Strength 72.4 MPa. Diskritisasi Metode Elemen Hingga (MEH) pada desain botol Rubicks v. 2.1 menghasilkan jumlah elemen sebanyak 26.206 Elemen dan jumlah Node sebanyak 51.732 Nodes yang memiliki bentuk elemen tetrahedral.

Pada penelitian ini akan diberikan variasi gaya pada salah satu permukaan botol. Hasil yang akan dicari diberikan adalah deformasi total yang terjadi pada desain botol Rubicks v. 2.1, tegangan geser maksimum untuk mencari desain yang efektif dan faktor keamanan dari botol Rubicks v. 2.1. [8]. Software yang digunakan pada simulasi metode elemen hingga adalah ANSYS 16.0.

\subsection{Desain Botol Rubicks v. 2.1}

Desain botol plastik Rubicks v. 2.1 .memiliki spesifikasi seperti pada Gambar 1. Gambar 1. (a) Botol Rubicks v.2.1 memiliki bentuk seperti balok dengan dua lubang ditengah. Selain itu terdapat lubang dibawah agar dapat disambung dengan bagian atas botol. Pada Gambar 1 (b) Tampak Samping dan (c) Tampak Atas, terdapat spesifikasi bentuk dan ukuran dalam skala millimeter (mm) botol Rubicks v. 2.1. Keseluruhan botol memiliki tebal sebesar $1 \mathrm{~mm}$.

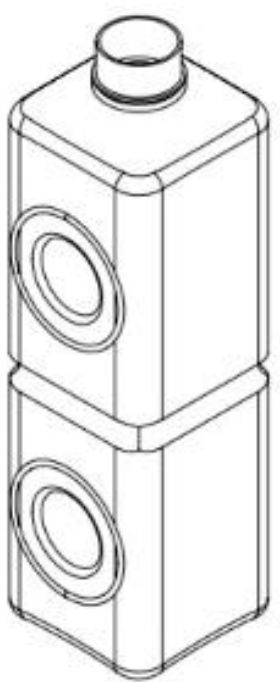

A

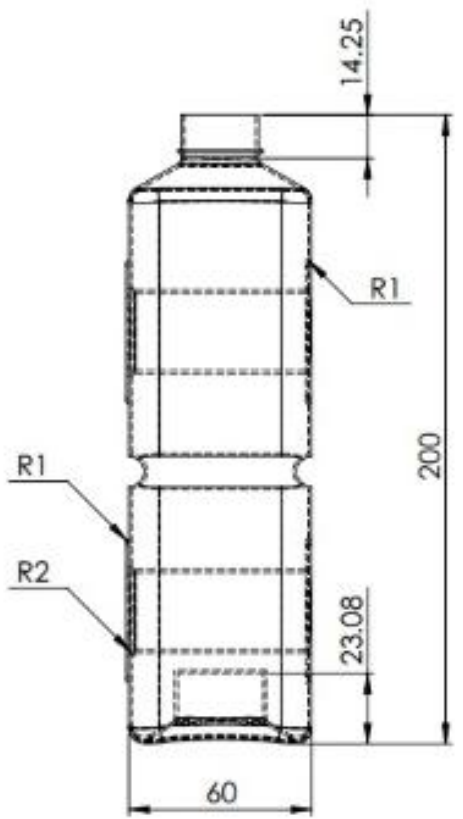

b

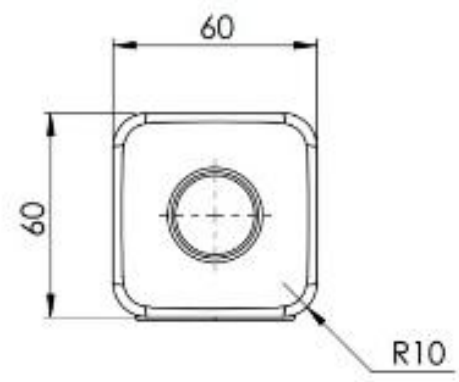

c

\subsection{Pemberian Gaya dan Tumpuan}

Gambar 1. (a) Botol Rubicks v. 2.1 (b) Tampak Samping (c) Tampak Atas

Gaya diberikan pada bagian depan botol dan pada bagian belakang botol diberikan tumpuan tetap. Pemberian gaya pada botol memiliki variasi beban sebesar: $200 \mathrm{~N}, 400 \mathrm{~N}, 600 \mathrm{~N}, 800 \mathrm{~N}, 1000 \mathrm{~N}, 1200 \mathrm{~N}, 1400 \mathrm{~N}, 1600 \mathrm{~N}, 1800 \mathrm{~N}$, 2000 N. Pada saat botol diberi gaya, kondisi botol diasumsikan bahwa tekanan di dalam botol tetap, dan tidak ditutup dengan tutup botol. Asumsi tersebut digunakan agar tidak terjadi gaya tekan yang tertahan pada saat botol diberi gaya. Posisi botol diletakan dengan posisi horizontal, dapat dilihat pada Gambar 2. 


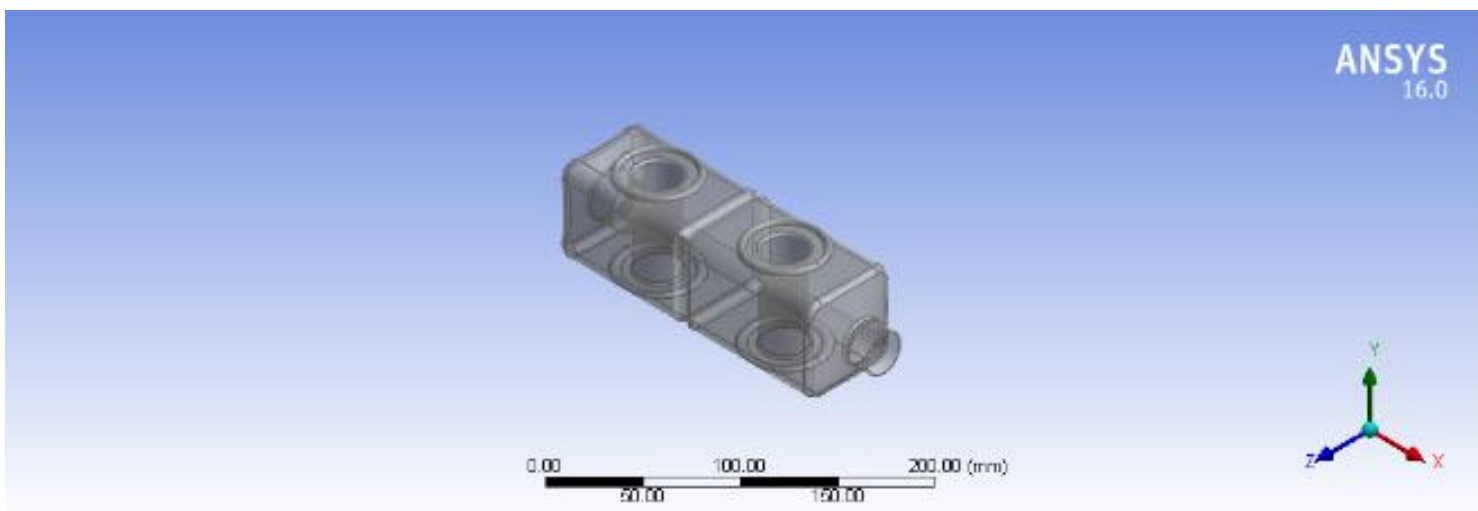

Gambar 2. Posisi Botol Rubicks v. 2.1

Area pemberian gaya dapat dilihat pada Gambar 3. Area pemberian gaya yaitu pada bagian muka botol Rubicks $v$. 2.1. Pemberian gaya pada permukaan muka botol merupakan asumsi bahwa botol diberikan gaya yang merata pada permukaan muka botol tersebut.

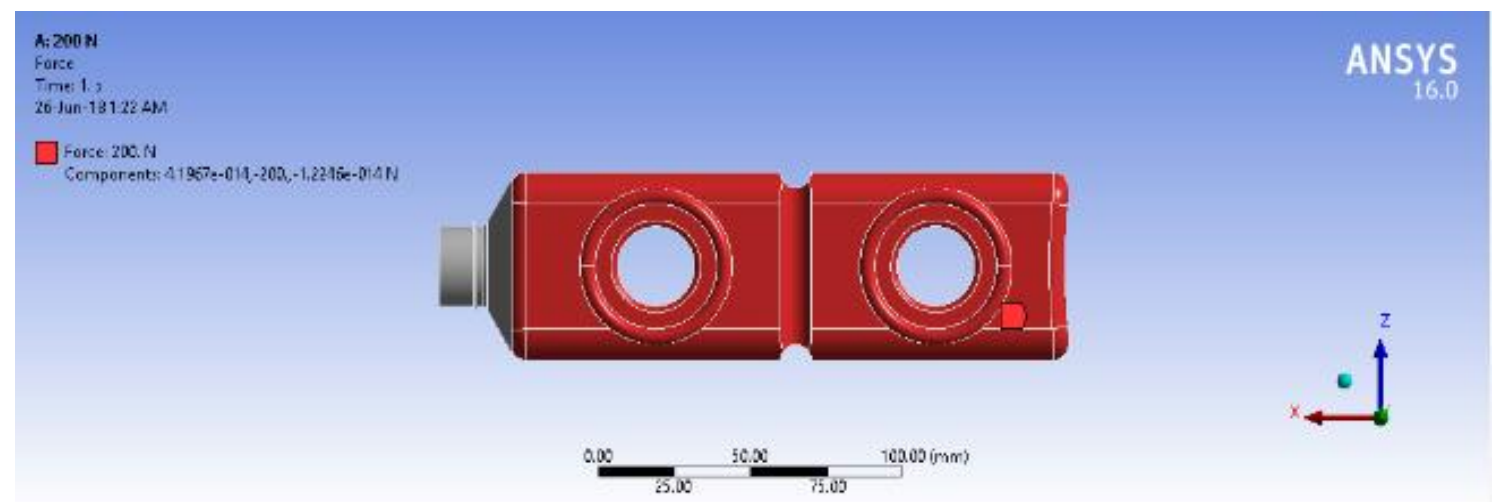

Gambar 3. Area Gaya yang Divariasikan

Area pemberian batas tumpuan tetap dapat dilihat pada Gambar 4 yaitu pada bagian belakang muka botol. Pada bagian tersebut dipilih area yang berkontak dengan permukaan bawah atau dasar.

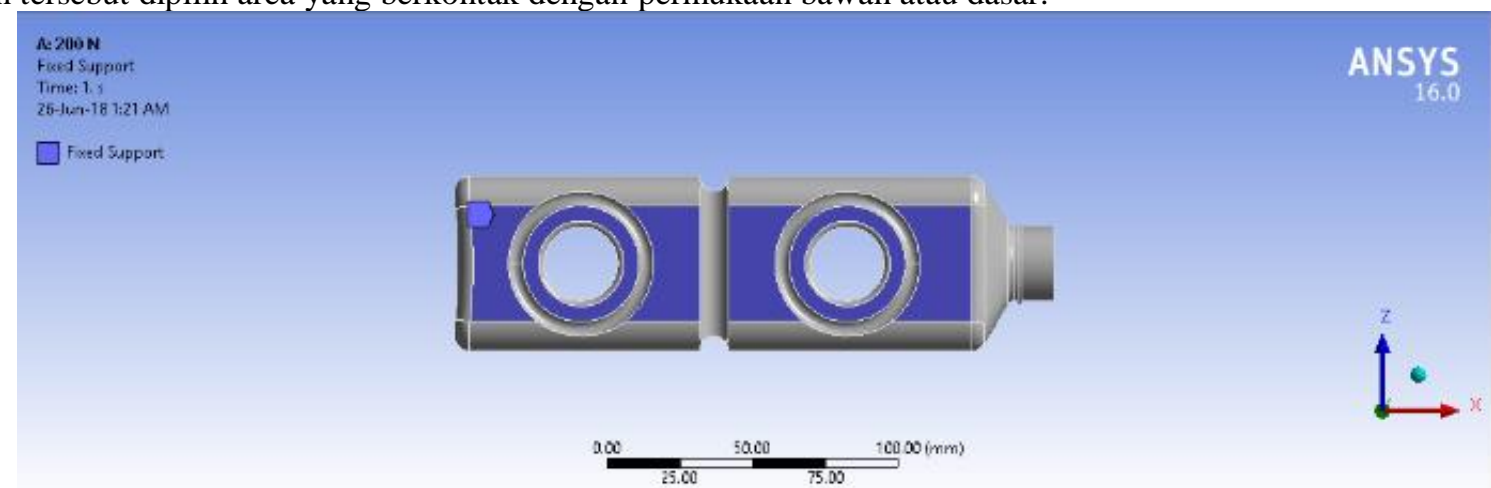

Gambar 4. Area Tumpuan Tetap

\section{Hasil dan pembahasan}

\subsection{Analisa Deformasi Total}

Pemberian gaya yang bervariasi menyebabkan perubahan terhadap nilai deformasi total dari botol tersebut. Deformasi merupakan perubahan bentuk botol pada arah sumbu-x, sumbu-y, dan sumbu-z. Dapat dilihat pada Gambar 5. Hasil deformasi total dari botol Rubicks v. 2.1 bahwa semakin besar gaya yang diberikan maka semakin besar deformasi total yang terjadi. Pada pemberian gaya minimum yaitu sebesar $200 \mathrm{~N}$ diperoleh deformasi total sebesar 0.22 $\mathrm{mm}$. Deformasi total tertinggi diperoleh saat diberi tegangan sebesar $2000 \mathrm{~N}$, yaitu mendapatkan nilai sebesar $2.25 \mathrm{~mm}$. 


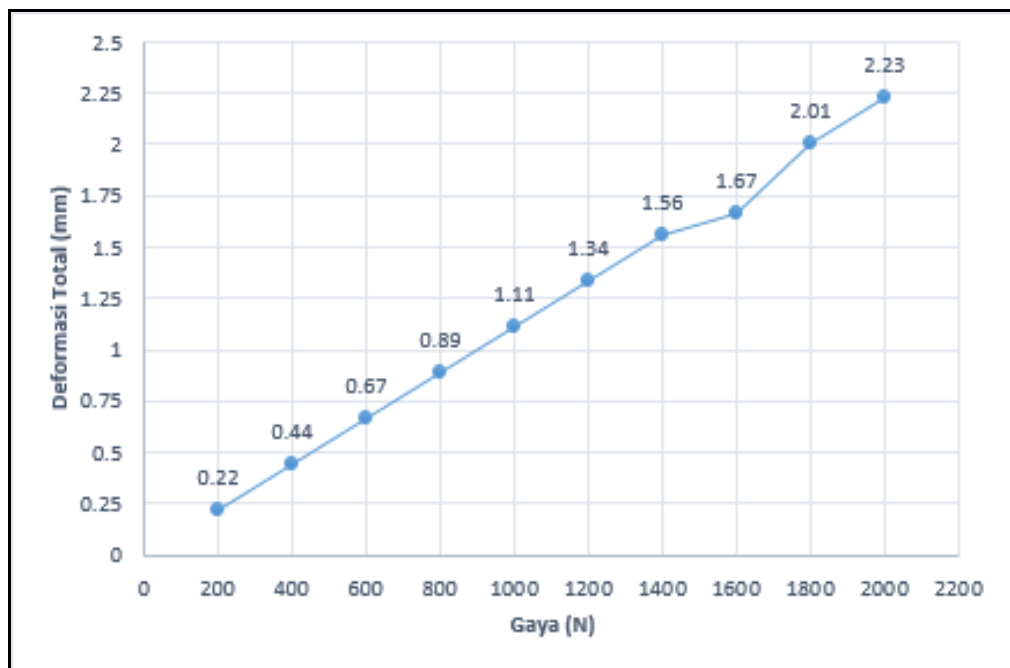

Gambar 5. Grafik Deformasi Total

Hasil dari simulasi pada saat diberikan gaya sebesar 2000 N dapat dilihat pada Gambar 6. Pada hasil simulasi tersebut dapat diketahui bahwa deformasi tersebesar terjadi pada permukaan muka botol.

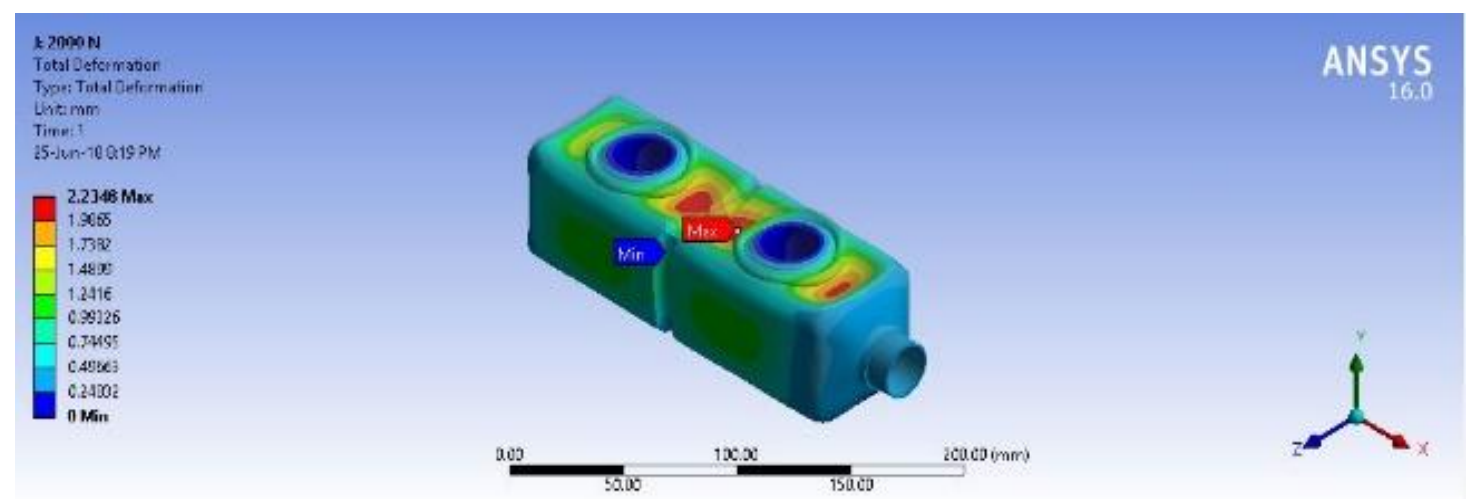

Gambar 6. Deformasi Total saat diberikan gaya 2000 N

\subsection{Analisa Tegangan Geser Maksimum}

Nilai tegangan geser maksimum telah didapatkan dengan variasi gaya yang diaplikasikan terhadap permukaan botol. Hasil variasi gaya terhadap tegangan geser maksimum dapat dilihat pada Gambar 7. Semakin besar gaya yang diberikan maka semakin besar tegangan geser maksimum yang terjadi pada permukaan botol. Tegangan Geser Maksimum saat diberikan gaya sebesar $200 \mathrm{~N}$ yaitu 3.66 MPa. Sedangkan tegangan geser maksimum pada saat diberikan gaya sebesar $2000 \mathrm{~N}$ adalah $36.65 \mathrm{MPa}$.

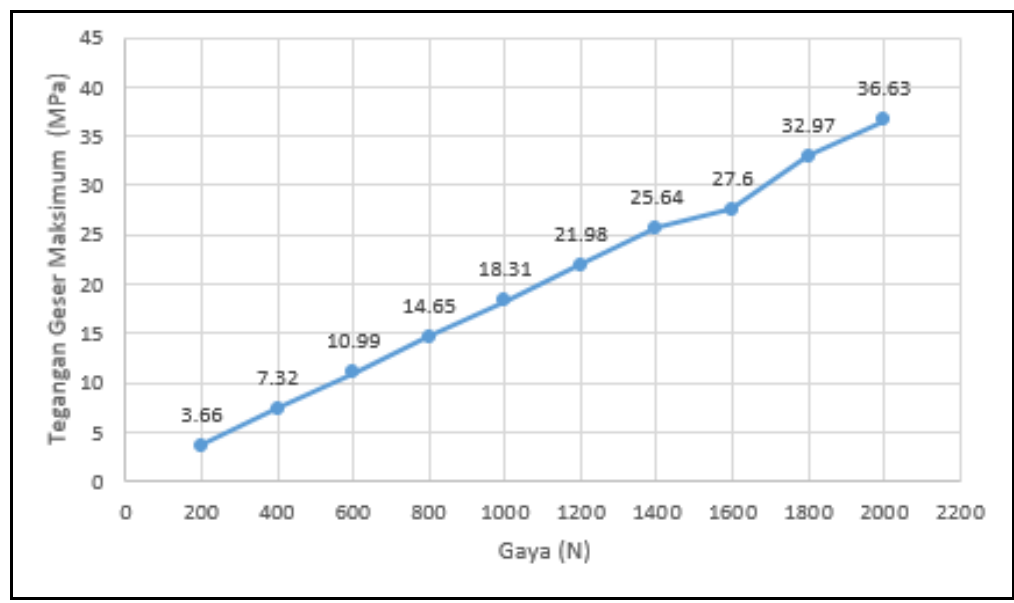

Gambar 7. Grafik Tegangan Geser Maksimum 
Hasil simulasi saat diberikan gaya sebesar $2000 \mathrm{~N}$ dapat dilihat pada Gambar 8. Pada hasil simulasi tersebut dapat diketahui bahwa tegangan geser maksimal terjadi pada permukaan muka botol yang berada di sekitar lubang botol.

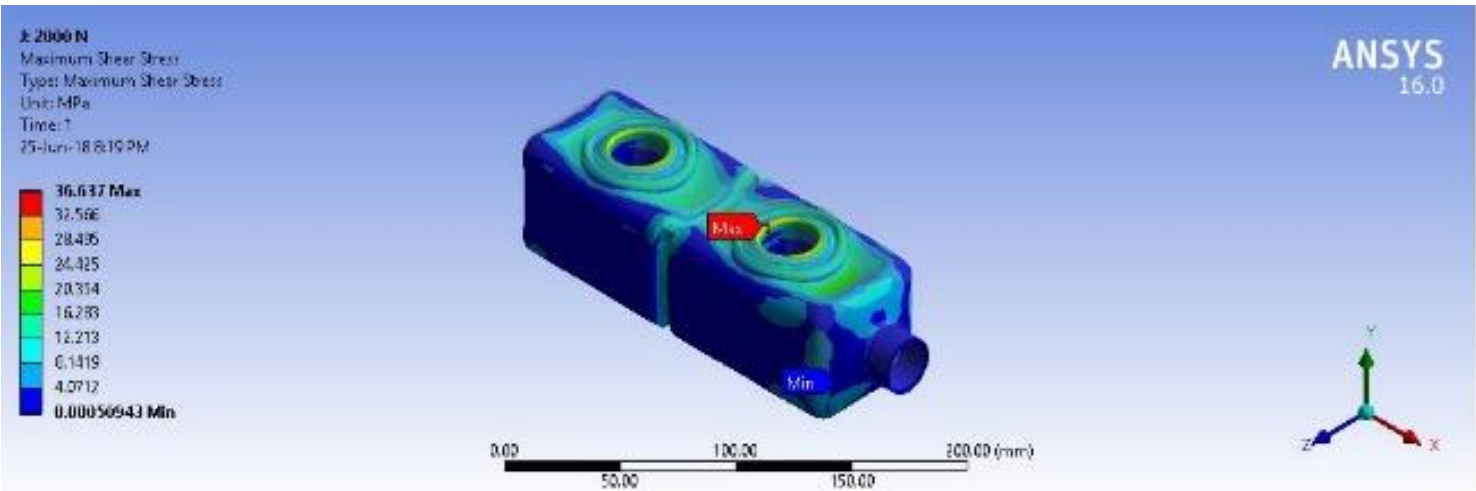

Gambar 8. Hasil Simulasi Tegangan Geser Maksimum saat diberi gaya 2000 N

\subsection{Analisa Faktor Keamanan}

Faktor keamanan pada botol Rubicks v. 2.1 dapat menunjukan besar gaya yang dapat ditahan oleh struktur desain botol. Hasil gaya yang diberikan terhadap faktor keamanan dapat dilihat pada Gambar 9. Dapat dilihat bahwa semakin besar gaya yang diberikan maka semakin kecil faktor keamanannya. Pada awal diberikan gaya sebesar $200 \mathrm{~N}$ menghasilkan faktor keamanan sebesar 8.1. Pada saat diberikan gaya $2000 \mathrm{~N}$ didapatkan faktor keamanan sebesar 0.8.

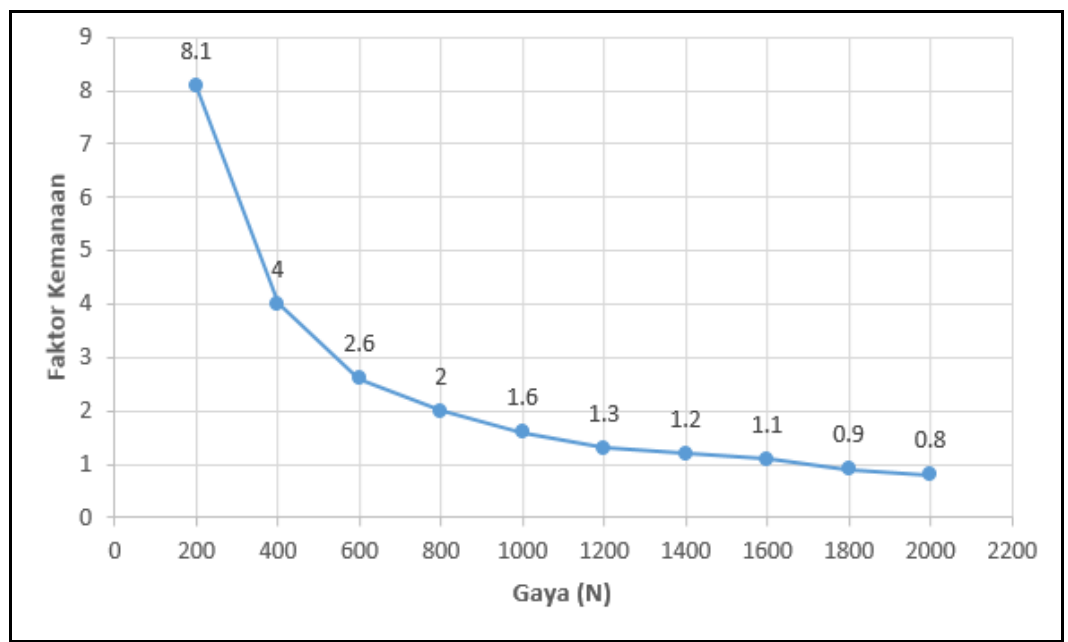

Gambar 9. Grafik Faktor Keamanan

Hasil simulasi pada saat diberikan gaya sebesar $2000 \mathrm{~N}$ dapat dilihat pada Gambar 10. Pada hasil simulasi tersebut dapat diketahui bahwa faktor keamanan dari botol paling rendah yaitu 0.8. Pada kondisi faktor keamanan tersebut permukaan muka botol memiliki kontur warna yang sama.

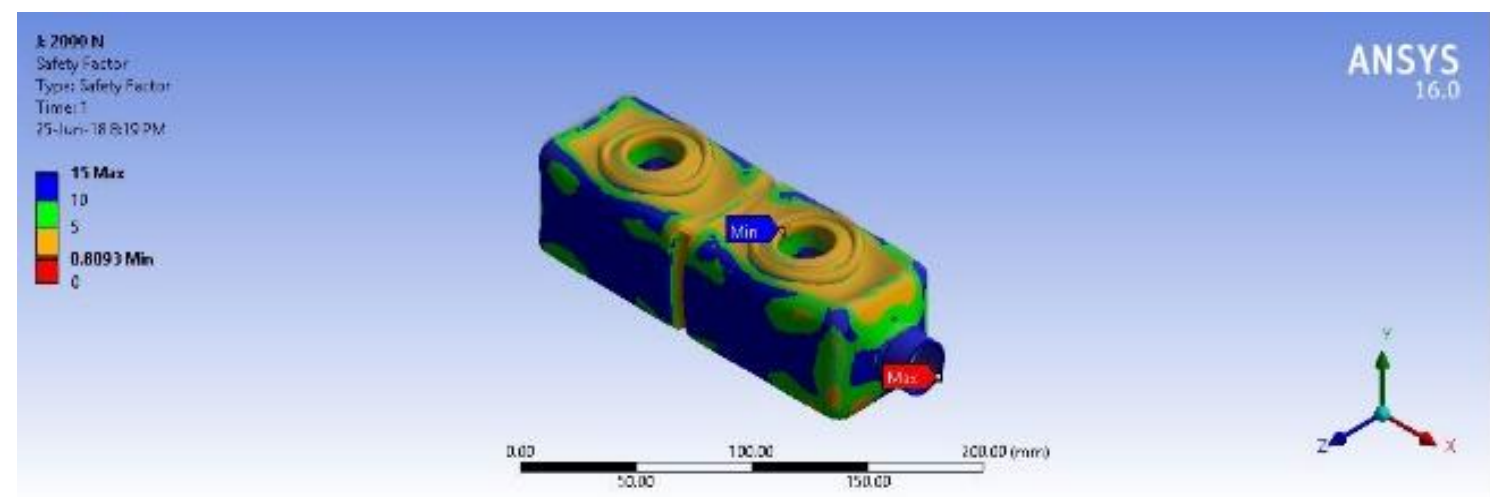

Gambar 10. Hasil Simulasi Faktor Keamanan pada saat diberikan gaya sebesar 2000 N 


\subsection{Hubungan Tegangan Geser Maksimum dengan Faktor Keamanan}

Dari hasil analisa tegangan geser maksimum dan faktor keamanan, kedua hal tersebut memiliki hubungan yang erat. Dapat dilihat pada Tabel 1 semakin besar gaya yang diberikan maka semakin besar nilai tegangan geser maksimum. Semakin besar gaya dan tegangan geser maksimum maka semakin kecil faktor keamanan dari botol tersebut.

Tabel 1. Hubungan Gaya, Tegangan Geser Maksimum dan Faktor Keamanan

\begin{tabular}{ccc}
\hline Gaya $(\mathbf{N})$ & Tegangan Geser Maksimum (MPa) & Faktor Keamanan \\
\hline 200 & 3.66 & 8.1 \\
400 & 7.32 & 4 \\
600 & 10.99 & 2.6 \\
800 & 14.65 & 2 \\
1000 & 18.31 & 1.6 \\
1200 & 21.98 & 1.3 \\
1400 & 25.64 & 1.2 \\
1600 & 27.6 & 1.1 \\
1800 & 32.97 & 0.9 \\
2000 & 36.63 & 0.8 \\
\hline
\end{tabular}

Dapat diketahui bahwa tegangan yang menyebabkan desain botol plastik Rubicks v. 2.1 memasuki titik luluh adalah ketika faktor keamanan $\leq 1$. Dari Tabel 1 dapat diinterpolasi bahwa tegangan geser maksimum yang memiliki faktor keamanan 1 yaitu sebesar 30.28 MPa. Maka desain botol plastik Rubicks v. 2.1 mampu menahan beban sampai titik luluh pada saat tegangan geser maksimum tersebut, atau senilai dengan gaya sebesar $1700 \mathrm{~N}$.

\section{Kesimpulan}

Desain dan analisa botol Rubicks v. 2.1 dengan metode elemen hingga sudah dilakukan. Analisa desain bertujuan untuk menemukan nilai deformasi total, tegangan geser maksimum dan faktor keamanan dengan memberikan sepuluh variasi gaya pada permukaan depan botol. Dari hasil analisa diperoleh hasil bahwa semakin besar gaya yang diberikan maka deformasi total dan tegangan geser maksimum akan semakin bertambah namun faktor keamanan dari desain botol plastik Rubicks v. 2.1 terus menurun seiring bertambahnya gaya yang diberikan. Adapun analisa menggunakan metode elemen hingga didapatkan nilai maksimum deformasi total adalah $2.25 \mathrm{~mm}$, dan tegangan geser maksimum terbesar 36.65 MPa. Dari hasil hubungan gaya dengan faktor keamaan, maka gaya yang mampu diberikan pada desain botol plastik Rubicks v. 2.1 adalah sebesar $1700 \mathrm{~N}$.

\section{Daftar Pustaka}

[1] Atkin, E., 2018, The Global Crisis of Plastic Pollution, https://newrepublic.com/article/147988/global-crisisplastic-pollution, diakses pada tanggal 27 Mei 2018.

[2] PT. SSE, 2017, Beverage Marketing Corporation and International Bottled Water Association, https://ptsse.co.id/berita/det ail/sampah-botol-plastik-akan-diapakan dia- kses pada tanggal 27 Mei 2018.

[3] Callister, W., Rethwisch, D., 2007, Materials science and engineering: an introduction, Materials Science and Engineering, Edisi Ketujuh, John Wiley \& Sons, Inc., New York.

[4] Matar, N. D, 2011, A Production-Recycling-Reuse Model For Plastic Beverages Bottles, Tesis, Universitas Ryerson: Kanada

[5] Nováková, K., Šeps, K., Achten, H., 2017, Experimental Development of a Plastic Bottle Usable as a Construction Building Block Created out of Polyethylene Terephthalate: testing Reference, Journal of Building Engineering, Elsevier Ltd. Volume 12, Juli 2017, Halaman 239-247.

[6] Nováková, K. 2016. Building Unit of Plastic, In Particular Bottle-Shaped. Europe Patent EP3 $101189 \mathrm{~B} 1$.

[7] Rogers, A. M., 2016, Botbrick - The Reusable Bottle Plastic Solution, https:// www.botbrik.com/contact-us/, diakses pada tanggal 26 Mei 2018.

[8] Budynas, R., Nisbett, 2008, Shigley’s Mechanical Engineering Design, Eighth Edition, McGraw-Hill, New York. 